\title{
MAPPING SLEEPING SICKNESS IN WeSTERN AfRICA IN A CONTEXT OF DEMOGRAPHIC TRANSITION AND CLMATE CHANGE
}

\author{
CECCHI G.*, COURTIN F.**, PAONE M.*, DIARRA A.****, FRANCO J.R.***, MATTIOLI R.C.** \& SIMARRO P.P.***
}

\section{Summary:}

Human population growth, climate change and economic development are causing major environmental modifications in Western Africa, which will have important repercussions on the epidemiology of sleeping sickness. A new initiative, the Atlas of human African trypanosomiasis (HAT), aims at assembling and geo-referencing all epidemiological data derived from both active screening activities and passive surveillance. A geographic database enables to generate up-to-date disease maps at a range of scales and of unprecedented spatial accuracy. We present preliminary results for seven West African countries (Benin, Burkina Faso, Côte d'lvoire, Ghana, Guinea, Mali and Togol and briefly discuss the relevance of the Atlas for future monitoring, control and research activities.

KEY WORDS : human African trypanosomiasis, GIS, atlas, health geography, disease ecology.

\section{INTRODUCTION}

T Two sub-species of the parasitic protozoan Trypanosoma brucei, T. b. gambiense Dutton 1902 and T. b. rhodesiense Stephens and Fantham 1910, are the causative agents of human African trypanosomiasis (HAT), commonly known as sleeping sickness. Trypanosomes are transmitted by the bite of the bloodsucking tsetse fly (genus Glossina) and the ensuing infection is lethal if untreated. The Gambian form of the disease occurs in Central and Western Africa and it accounts for over 90 percent of HAT reported cases (Simarro et al., 2008). It is a chronic and ultimately

\footnotetext{
* Food and Agriculture Organization of the United Nations (FAO), Animal Production and Health Division, Viale delle Terme di Caracalla, 1, 00153, Rome, Italy.

** Centre International de Recherche Développement sur l'Élevage en zone Subhumide (CIRDES), Institut de Recherche pour le Développement (IRD), UMR 177, Bobo-Dioulasso, Burkina Faso.

*:** World Health Organization, Control of Neglected Tropical Diseases, Innovative and Intensified Disease Management, 1211 Geneva 27, Switzerland.

**:*** World Health Organization, Regional Office for Africa, Brazzaville.

Correspondence: Pere P. Simarro.

Tel.: +41 227911345 - Fax +41 227914777 - E-mail: SimarroP@who.int
}

Résumé : CARTOGRAPHIE DE LA TRYPANOSOMOSE HUMAINE AFRICAINE EN AFrique de l'OUest Dans un CONTEXTE De transition DÉMOGRAPHIQUE ET DE CHANGEMENT CLIMATIQUE

La croissance démographique, le changement climatique et le développement économique provoquent des transformations environnementales majeures en Afrique de l'Ouest, qui ne sont pas sans conséquences sur l'épidémiologie de la trypanosomose humaine africaine (THA). Une nouvelle initiative, l'Atlas de la THA, vise à rassembler et géoréférencer les données épidémiologiques dérivées des prospections médicales et de la surveillance passive. Cette base de données spatialisée permet de créer des cartes actualisées de la maladie, à différentes échelles et d'une précision sans précédent. Nous présentons les résultats préliminaires pour sept pays de l'Afrique de l'Ouest (Bénin, Burkina Faso,

Côte d'lvoire, Ghana, Guinée, Mali et Togol et nous examinons l'importance de l'Atlas pour les futures activités de surveillance, de control et de recherche.

MOTS CLÉS : trypanosomose humaine africaine, SIG, atlas, géographie de la santé, écologie des maladies.

lethal disease with a long asymptomatic stage that may last several years following the onset of the infection. Rhodesian sleeping sickness is an acute form that is found in Southern and Eastern Africa, with death usually occurring within six months of the onset of overt clinical symptoms (Apted, 1970).

The relationship between human populations, climate, and the ecology of this vector-borne disease has unfolded over evolutionary time. Changes in African climate in the last 5-6 million years are thought to have mediated important modifications in the African environment and in its mammalian fauna. These phenomena appear to have marked important milestones in the evolution of hominids and in the emergence of the genus Homo (deMenocal, 2004). In particular, the expansion of savannah grasslands is thought to have greatly influenced the evolution and behaviour of early humans (Clark, 1980). The transition from forest habitat to savannah is also believed to represent a turning point in the relation between apes and primate-infective trypanosomes. Early hominids that would have become adapted to T. $b$. gambiense in their ancestral home in the forests would have entered into contact with $T . b$. rhodesiense circulating in the savannah game animal reservoir. It has also been speculated that the 
attempt to avoid tsetse infested areas may have contributed to driving our ancestors out of the Rift Valley and eventually 'out of Africa' (Welburn et al., 2001). In historical times, ecological factors have continued to play a key role in sleeping sickness epidemiology. Although documents dating back to the pre-colonial period are limited, it is commonly believed that the profound social changes caused by colonization created conditions conducive to HAT outbreaks of epidemic proportions. In the Pax Britannica epidemiology it was posited that pacification of warring groups by colonial authorities would have brought people to farm and travel into previously inaccessible forested areas inhabited by tsetse fly, thus leading to disease spread and amplification (Duggan, 1962). From a more explicitly ecological perspective, Ford argued that colonization had brought about the problem by disrupting the balance between parasite, fly, people, flora and fauna, thus radically altering the epidemiological interplay (Ford, 1971).

Western Africa offers an interesting case study for understanding how climate, human population dynamics and environmental changes have influenced HAT epidemiology in the last one hundred years. It has been shown that the regional evolution of HAT foci, including their establishment, spread and extinction, and the shifts between endemic or epidemic condi- tions, can largely be explained in the light of human migrations and climate- and human-induced tsetse habitat modifications (Courtin et al., 2008). At the same time, the qualitative nature of these studies has demonstrated that more accurate and comprehensive information on HAT spatial distribution is needed to develop credible scenarios on its probable future course.

To meet this need, the World Health Organization (WHO) and the Food and Agriculture Organization of the United Nations (FAO) jointly launched "the Atlas of HAT". The initiative is implemented in the framework of the Programme against African Trypanosomiasis (PAAT) and it aims at updating the epidemiological picture of sleeping sickness across the whole of sub-Saharan Africa. Mapping relies on Geographic Information Systems (GIS) and it is based on recent field work carried out by National Sleeping Sickness Control Programmes (NSSCPs), Non-Governmental Organizations (NGOs) and research institutions. Most of these field activities were supported by WHO and they generated a considerable amount of epidemiological information, little of which has been published. The WHO/FAO initiative first targeted six countries in Central Africa, thus enabling to develop both the methodology for geo-referencing HAT cases and the database (DB) of HAT (Cecchi et al., 2009). In this paper we briefly describe our approach to HAT global

$20^{\circ} \mathrm{W}$

$0^{\circ}$

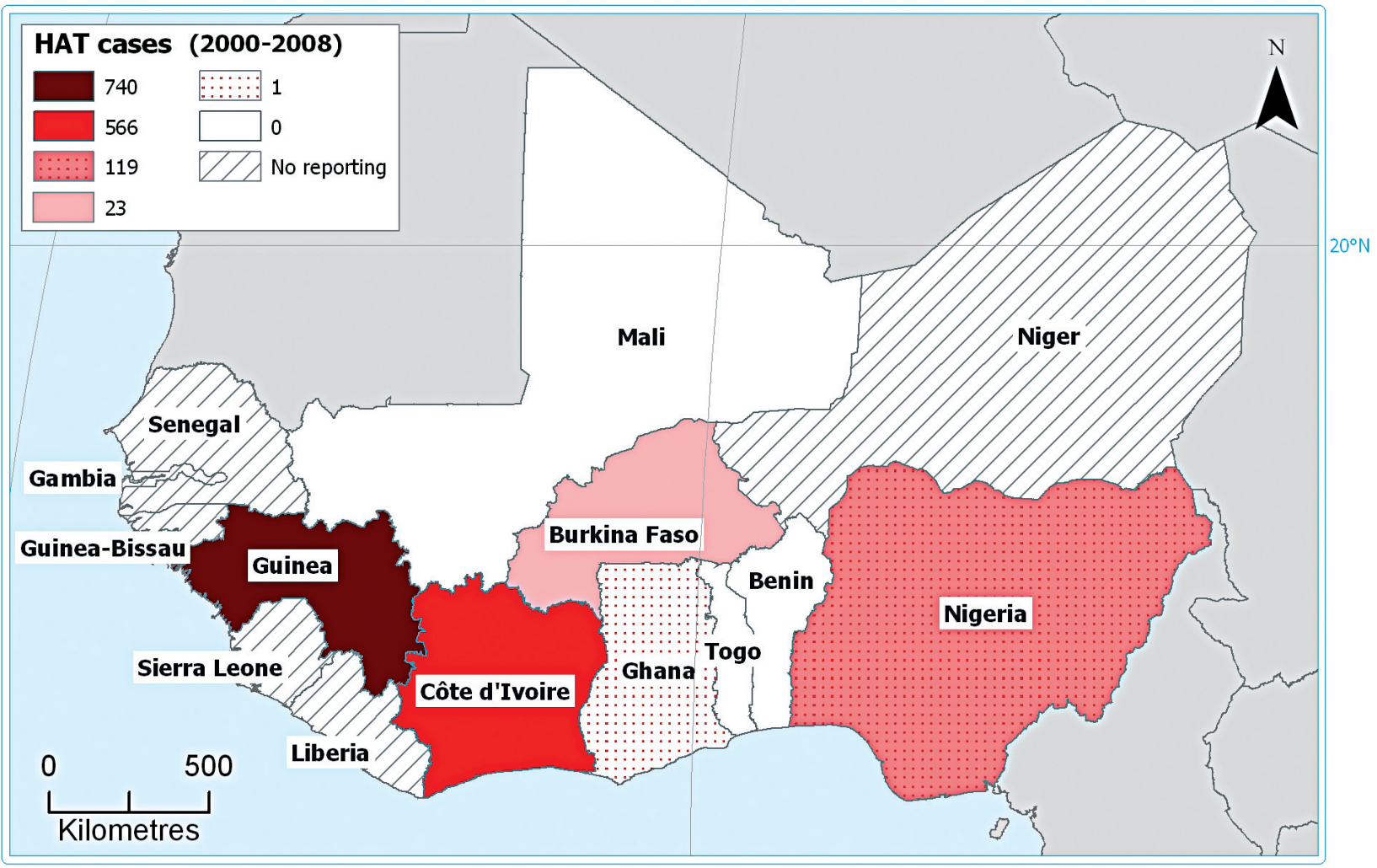

Fig. 1. - HAT cases reported from Western Africa in the period 2000-2008 (data source: WHO). 
mapping and we present preliminary results for seven West African countries (Benin, Burkina Faso, Côte d'Ivoire, Ghana, Guinea, Mali and Togo), which account for over 90 percent of the HAT cases reported from Western Africa in the period 2000-2008.

\section{MATERIALS AND METHODS}

A 11 countries of Western Africa are considered endemic for Gambian sleeping sickness (Simarro et al., 2008). We use here the definition of Western Africa region that is customary in the United Nations, thus including Benin, Burkina Faso, Côte d'Ivoire, Gambia, Ghana, Guinea, Guinea-Bissau, Liberia, Mali, Niger, Nigeria, Senegal, Sierra Leone and Togo (we do not consider the trypanosomiasis-free Cape Verde archipelago). In Figure 1 the number of HAT cases reported by each country in Western Africa is shown (reporting period 2000-2008).

Figure 1 does not include individuals with suspected infections that were reported from Benin and Mali between 2000 and 2003. External technical support provided to the NSSCPs of these two countries could not confirm the suspicion, and subsequent surveys did not show any evidence of the presence of trypanosomes in the suspected areas.

Although highly informative, the type of country-level aggregate shown in Figure 1 is of limited value if the complex epidemiological dynamics at play are to be captured. Besides, it is inadequate to understand how disease distribution evolves in space and time, which in turn is crucial to the targeting of screening and control activities.

Over the last ten years WHO has been collating abundant epidemiological information from NSSCPs, NGOs and research institutes. Most epidemiological reports contain information on the locations of epidemiological interest. In this context, we define locations of epidemiological interest those where active screening is carried out, as well as those locations from which HAT cases are reported by means of passive surveillance. This geographic information, coupled with disease data, is systematically analyzed to generate the Atlas of HAT.

Key to the production of the Atlas is the accurate measurement of the geographic coordinates (latitude and longitude) of all locations of epidemiological interest. When coordinates acquired by Global Positioning System (GPS) are available, they are preferred for the Atlas as GPS provides a high level of spatial accuracy. If GPS coordinates are not available for a given site, the location's recorded name can be used to search for geographic coordinates. Our main source of georeferenced populated places is the GEOnet Names Server (GNS) database of the Unites States National
Geospatial-Intelligence Agency, which is complemented by other gazetteers available in the public domain. Data from the WHO's Public Health Mapping and GIS programme and a range of paper and digital maps are also used.

The geographic information (names and coordinates of locations) and disease data (i.e. number of new HAT cases, number of people screened, reporting year, human population census, surveillance type (either active or passive), parasite sub-species, disease stage) are stored in a database. Importantly, we keep track of all data sources, which are also assembled in a centralized data repository.

\section{RESULTS}

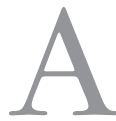

t the time of writing, over a hundred reports and files from the seven study-countries have 1 been analyzed. Approximately a quarter of HAT cases reported for the study period 2000-2008 are derived from passive surveillance, and the remainder resulted from active screening of over 330,000 people. A total of 1,010 locations of epidemiological interest have been analyzed, among which approximately 88 percent could be mapped. Geo-referenced locations account for 1,064 HAT cases, which correspond to approximately 80 percent of all cases reported from the seven study-countries (study-period 2000-2008). Activities are ongoing to improve and refine this preliminary output, especially in order to geo-reference those reported cases that have not been mapped at the village level yet.

Table I shows the country-level summary of the geo-referencing activity, whose results are shown in Figure 2. Figure 2A shows risk areas in West Africa based on active and historical foci as they were assembled for WHO in the nineties, without using geo-referencing techniques. The full map covers the whole of sub-Saha-

\begin{tabular}{lccccc}
\hline & Geographic locations & & \multicolumn{2}{c}{ HAT cases } \\
\cline { 2 - 3 } \cline { 5 - 6 } Country & $\begin{array}{c}\text { Reported } \\
\text { (number) }\end{array}$ & $\begin{array}{c}\text { Mapped } \\
(\%)\end{array}$ & & $\begin{array}{c}\text { Reported } \\
\text { (number) }\end{array}$ & $\begin{array}{c}\text { Mapped } \\
(\%)\end{array}$ \\
\hline Benin & 182 & 83.5 & & 0 & - \\
Burkina Faso & 32 & 96.9 & & 23 & 8.7 \\
Côte d'Ivoire & 178 & 88.8 & & 566 & 62.5 \\
Ghana & 65 & 90.8 & & 1 & 100.0 \\
Guinea & 273 & 90.5 & & $740^{*}$ & 95.6 \\
Mali & 205 & 85.9 & & 0 & - \\
Togo & 75 & 84.0 & & 0 & - \\
\hline Total & 1,010 & 87.7 & & 1,330 & 80.0 \\
\hline
\end{tabular}

*Preliminary figure (official report for 2008 not yet available).

Table I. - Preliminary results of the geo-referencing of HAT cases. Reporting period: 2000-2008. Note: activities to map cases reported from Nigeria are in progress. 
(A)

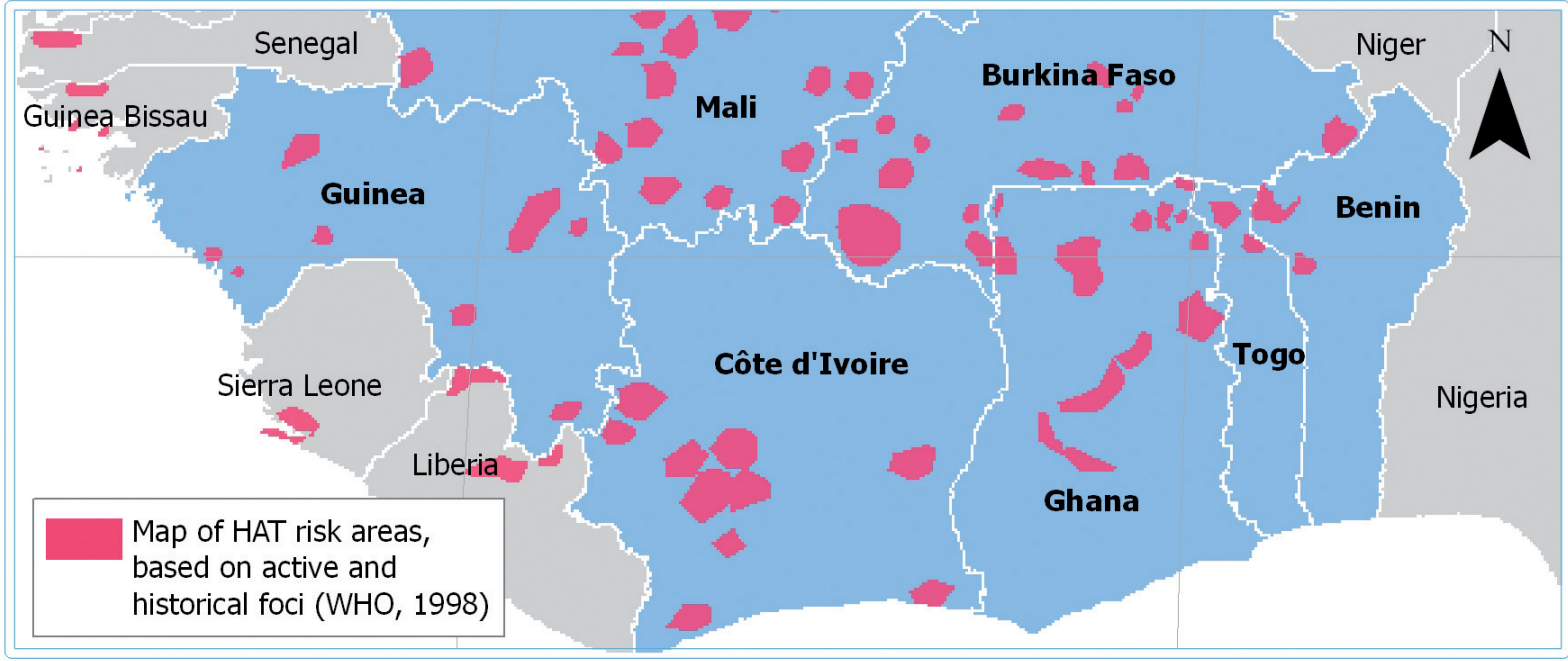

(B)

$10^{\circ} \mathrm{W}$

$0^{\circ}$

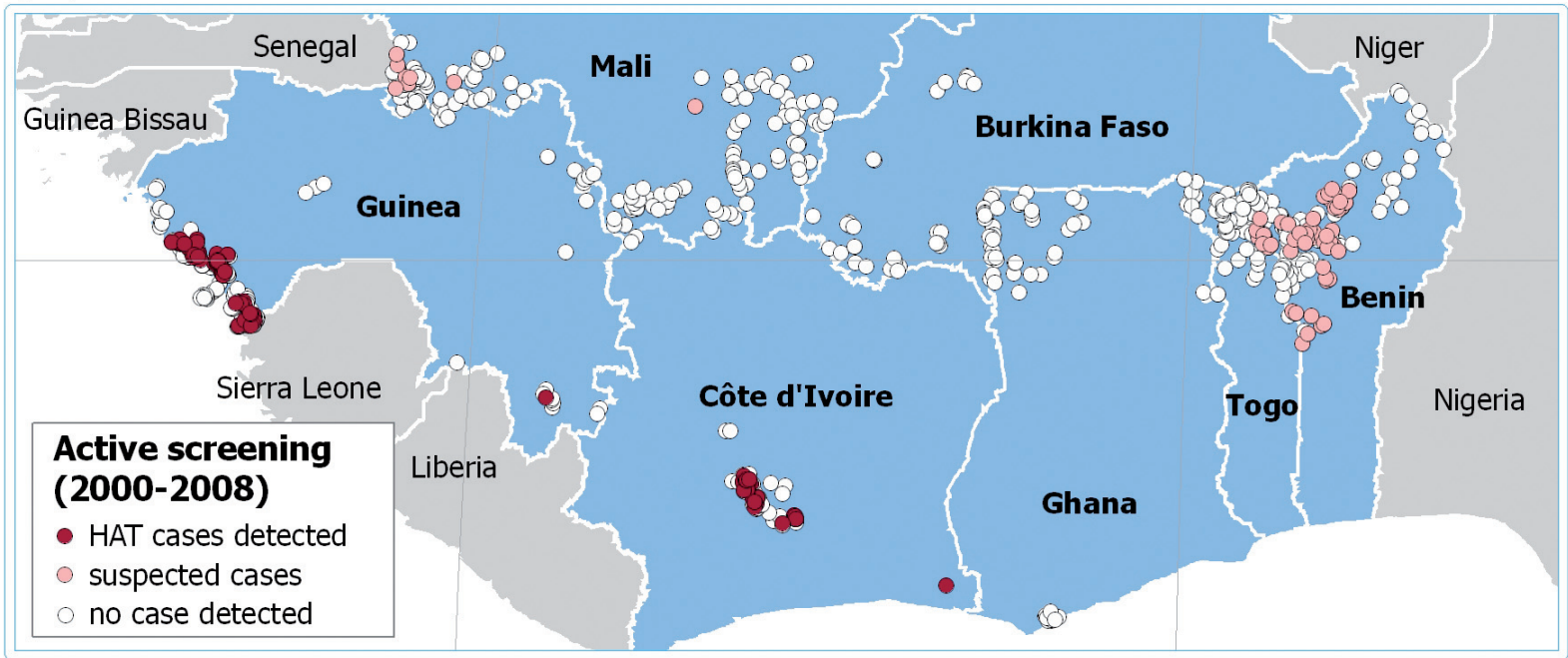

(C)

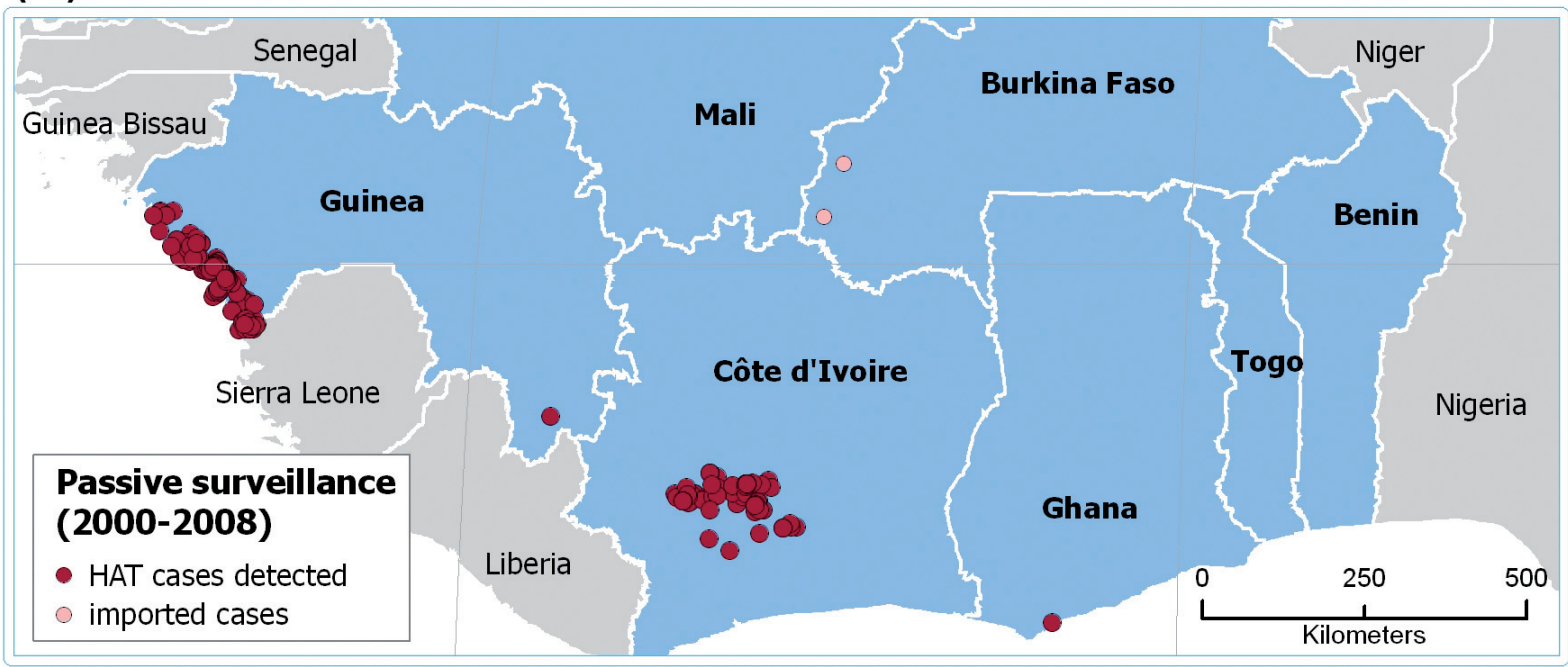

Fig. 2. - Distribution of (A) HAT risk areas (WHO, 1998), (B) actively reported and (C) passively reported HAT cases in the period 20002008. Study countries: Benin, Burkina Faso, Côte d'Ivoire, Ghana, Guinea, Mali and Togo (activities to map cases reported from Nigeria are in progress). 
ran Africa and it had been generated from formal and grey literature, as well as from expert opinion (WHO, 1998). We compare this previous cartographic product with two of the possible outputs that can be derived from the geo-database of HAT (Fig. 2B and C).

During the period 2000-2008 active screening in the seven study-countries (Fig. 2B) revealed significant levels of transmission in two regions: (1) West Central Côte d'Ivoire (Bonon, Bouaflé, Daloa and Sinfra areas) (2) Coastal Guinea (Boffa, Dubréka and Forécariah areas). These are two rather well investigated areas, where sustained levels of transmission had already been reported in past years (Courtin et al., 2005; Camara et al., 2005). Figure $2 \mathrm{~B}$ also shows that as from the year 2000 no case was detected through activities screening in over 500 distinct villages located in former areas of HAT transmission of Benin, Burkina Faso, Ghana, Mali and Togo.

The epidemiological picture drawn by active case finding is confirmed by the geographical distribution of passively reported cases (Fig. 2C). Among the passive cases we have analyzed over 66 percent were reported from coastal areas in Guinea, and most of the remaining cases originated from the focus of Bonon (Côte d'Ivoire). We also note that a few cases are occasionally reported from Burkina Faso. However, strong evidence suggests that these are not indigenous cases, but rather imported from migrants, most notably from coffee and cocoa plantations in disease-endemic areas in Côte d'Ivoire.

\section{DISCUSSION}

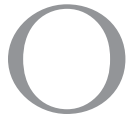
ur preliminary results are in agreement with previous studies that investigated the past and more recent trends in HAT epidemiology in Western Africa (Courtin et al., 2008). Numerous historical foci in the Sudanese and Guinean ecological zones have not shown evidence of active transmission in recent years. In Mali and Burkina Faso (as well as in the northern parts of Ghana, Togo and Benin) extensive, if not exhaustive, active screening in vast areas of historical endemicity has not detected cases of HAT in the period 2000-2008.

Significant disease prevalence only continues to be reported from Guinea and Côte d'Ivoire. In both cases, HAT transmission appears to be closely entwined with well defined agro-ecological settings. In Guinea, endemic locations fringe extensive mangrove swamps. This is clearly shown in Figure 3A, where HAT endemic locations are overlain onto the Globcover land cover map (Bicheron et al., 2006). In the mangrove biotope, HAT is known to affect rural people whose livelihoods rely on subsistence agriculture, salt extraction and fishery (Camara et al., 2005). In the mangrove foci of Guinea the contact between humans and tsetse flies, especially Glossina palpalis gambiensis Vanderplank 1949, is favoured by people's mobility within the mangroves, as well as by the presence of numerous natural water sources located in the vicinity of settlements (Camara et al., 2005).

In Côte d'Ivoire, most reported cases are clustered in the town of Bonon, mainly in the rural areas stretching south of the town. Figure $3 \mathrm{~B}$ illustrates that the land cover of this area is dominated by a mosaic of natural vegetation and cropland. In the focus of Bonon cultivation of cash crops such as cocoa and coffee favours the contact between agricultural workers and tsetse flies, especially the opportunistic species G.p.palpalis Robineau-Desvoidy 1830 (Fournet et al., 1999; Courtin et al., 2005).

The association between sleeping sickness occurrence in Western Africa and well delineated ecological settings could be exploited to identify priority areas for future active surveillance and control activities. In particular, land cover maps have proved very effective in describing and predicting different types of tsetse habitat (de la Rocque et al., 2001; Cecchi et al., 2008) and can thereby provide valuable input to decision making for tsetse and trypanosomiasis interventions.

Our preliminary results also show a marked clustering of the villages that have undergone active surveillance (Fig. 2B). It is clear that fairly extensive areas of Western Africa where HAT may still be endemic are still insufficiently studied. Nigeria, Sierra Leone and Liberia are arguably the three most notable gaps (the first one imputable to insecurity in the areas of transmission and the two latter cases largely ascribable to recent conflicts). Figure 3A shows how the northern part of the coast of Sierra Leone is characterized by land cover patterns that are similar to those found in the Forécariah focus located across the border with Guinea, thus suggesting potentially equivalent levels of transmission. The comprehensive and systematic review of HAT geographic distribution presently under way will help streamline future monitoring and control activities in these poorly investigated areas.

Further efforts will also be made to shed light on the epidemiological situation in such countries as Gambia, Guinea Bissau, Liberia, Niger and Senegal, where HAT reporting systems are presently not in place.

\section{CONCLUSIONS}

T $\mathrm{t}$ is predicted that in the next decades major environmental modifications will occur in Western Africa, driven by both endogenous and exogenous factors. In what is the most probable scenario, human population in the region is expected to grow by over 7 million a year (UN, 2007). This would imply surpassing 
the 600 million mark within 2050 (corresponding to a doubling of the present figure). Even though the vast majority of this growth will be absorbed by urban areas, a 20 percent increase in the next two decades is also expected in rural population (UN, 2008). The population surge is bound to increase pressure on the natural ecosystems, a phenomenon that will probably be compounded by agricultural losses due to climate change and climate variability. These losses have been estimated in the range between 2 and 4 percent of Gross Domestic Product before the turn of the century (Boko et al., 2007). It is believed that the ongoing envi- ronmental modifications will have drastic repercussions on the epidemiology and the spatial distribution of sleeping sickness in the region (Courtin et al., 2009). The intensification of agricultural activities and the reduction of average rainfall are likely to further erode tsetse habitat in the historical foci of the Sudanese and Guinean ecozones. This will reduce contact between humans and vector, thus limiting the risk of resurgence of HAT in these areas. On the other hand, population pressure compounded by climatic vagaries will probably exacerbate competition for land and water resources. Population displacements and migrations together
(A)

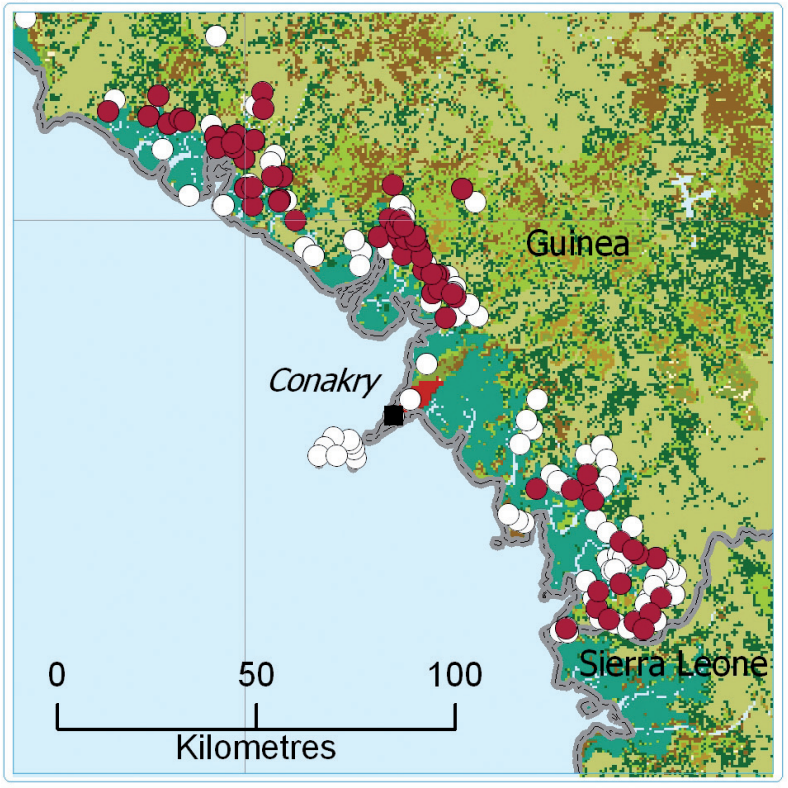

HAT active screening (2000-2008)

- HAT cases detected

- suspected cases

no case detected

\section{Land cover (Globcover, version 2.2)}

Closed (>40\%) broadleaved forest or shrubland
permanently flooded, saline or brackish water
Closed to open $(>15 \%)$ broadleaved evergreen
or semi-deciduous forest $(>5 \mathrm{~m})$
Open $(15-40 \%)$ broadleaved deciduous
forest/woodland $(>5 \mathrm{~m})$
Mosaic forest or shrubland $(50-70 \%)$
and grassland $(20-50 \%)$
Closed to open $(>15 \%)$ (broadleaved or needle-leaved,
evergreen or deciduous) shrubland ( $<5 \mathrm{~m})$
Mosaic grassland $(50-70 \%)$ and forest
or shrubland $(20-50 \%)$
Mosaic vegetation (grassland/shrubland/forest) $(50-70 \%)$
cropland ( $20-50 \%)$
Artificial surfaces and associated areas (Urban areas $>50 \%)$

(B)
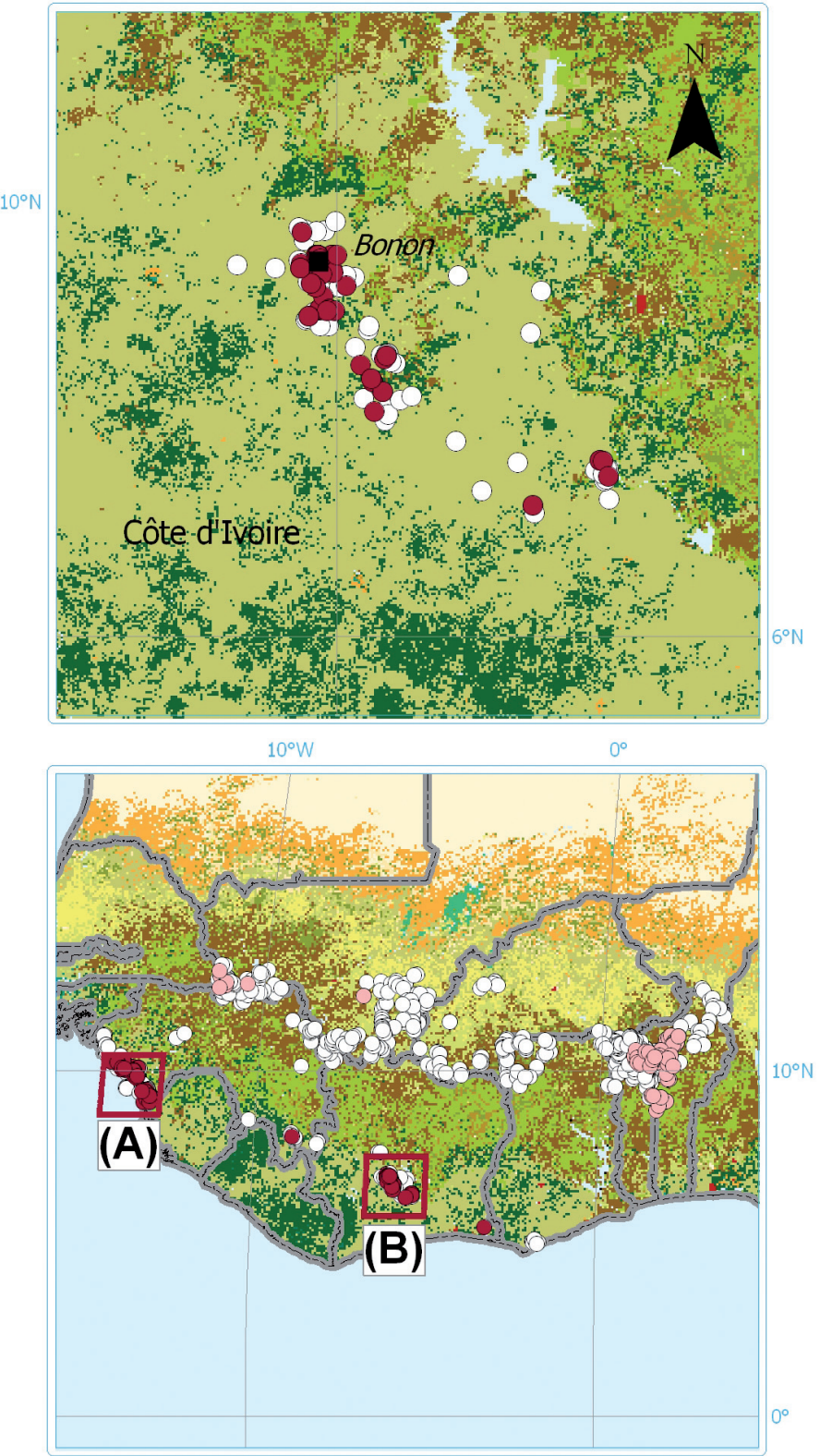

Fig. 3. - Distribution of HAT cases deriving from active surveillance carried out in the period 2000-2008. (A) Costal Guinea, (B) Bonon focus (Côte d'Ivoire). The underlying land cover map is Globcover (version 2.2, $300 \mathrm{~m}$ resolution, satellite imagery acquired between January 2005 and June 2006). In the legend, only the eight most relevant land cover classes that characterize zones A and B are shown. 
with the progressive loss of forested area to cropland, with an annual rate that in Western Africa is stably above 1 percent (FAO, 2007), may open new fronts of contact between humans and tsetse flies (e.g. in the remnants of rain forest that still survive in Liberia and Sierra Leone). Whether this could increase the risk of spreading HAT into previously unaffected areas is an open question, also linked to the debated role of domestic and wild animals as a reservoir of T. b. gambiense (WHO, 1998).

Coping with this rapidly evolving and diverse context will require tools capable of accurately following the evolution of the disease in space and time. In this paper we have described the first attempt ever to systematically collate data on HAT occurrence in Western Africa in a geographic information system. The Atlas of HAT will provide critical information to monitor the disease and to estimate how climate and human population dynamics will impact on the epidemiology of sleeping sickness in the $21^{\text {st }}$ century.

\section{ACKNOWLEDGEMENTS}

W Te gratefully acknowledge all institutions that, through WHO, provided input to this study. First and foremost we wish to thank the Ministries of Health and the NSSCPs of Benin, Burkina Faso, Côte d'Ivoire, Ghana, Guinea, Mali and Togo. Epidemiological and geographical data were also provided by the Institut de Recherche pour le Développement (IRD), Institut Pierre Richet (IPR), Projets de Recherches Cliniques contre la Trypanosomiase (PRCT), Centre International de Recherche-Développement sur l'Élevage en zone Sub-humide (CIRDES), Direction Régionale de la Santé de la région du Houët (Burkina Faso), and Centre de coopération Internationale en Recherche Agronomique pour le Développement (CIRAD). We also acknowledge the financial contribution of WHO and of the International Fund for Agricultural Development (IFAD).

\section{REFERENCES}

APTED F.I.C. Clinical manifestations and diagnosis of sleeping sickness, in: The African trypanosomiasis. Mulligan H.W. (ed.), George Allen \& Unwin, London, 1970, 661-683.

Bicheron P., Leroy M., Brockmann C., Krämer U., Miras B., Huc M., Ninõ F., Defourny P., Vancutsem C., Arino O., Ranéra F., Petit D., Amberg V., Berthelot B. \& Gross D. Globcover: a $300 \mathrm{~m}$ global land cover product for 2005 using Envisat Meris time series, in: Proceedings of the Recent advances in quantitative remote sensing symposium, Valencia, September 2006.

Boko M., Niang I., Nyong A., Vogel C., Githeko A., Medany M., Osmanelasha B., Tabo R. \& Yanda P. Africa, in: Climate change 2007: impacts, adaptation and vulnerability. Contribution of Working group II to the Fourth assessment report of the intergovernmental panel on climate change. Parry M.L., Canziani O.F., Palutikof J.P., van der Linden P.J. \& Hanson C.E. (eds), Cambridge University Press, Cambridge, 2007, 433-467.

Camara M., Kaba D., Kagbadouno M., Sanon J.R., Ouendeno F.F. \& Solano P. La trypanosomose humaine africaine en zone de mangrove en république de Guinée : caractéristiques épidémiologiques et cliniques de deux foyers voisins. Médecine Tropicale, 2005, 65, 155-161.

Cecchi G., Mattioli R.C., Slingenbergh J. \& De la Roceue S. Land cover and tsetse fly distributions in sub-Saharan Africa. Medical and Veterinary Entomology, 2008, 22, 364373.

Cecchi G., Paone M., Franco J.R., Fèvre E.M., Diarra A., Ruiz J.A., Mattioli R.C., \& Simarro P.P. Towards the Atlas of human african trypanosomiasis. International Journal of Health Geographics, 2009, 8, 15.

CLARK J.D. Early human occupation of African savanna environments, in: Human ecology in savanna environments. Harris DR (ed.), Academic Press, London, 1980, 41-71.

Courtin F., Jamonneau V., Oke E., Coulibaly B., Oswald Y., Dupont S., Cuny G., Doumenge J.P. \& Solano P. Towards understanding the presence/absence of human African trypanosomosis in a focus of Côte d'Ivoire: a spatial analysis of the pathogenic system. International Journal of Health Geographics, 2005, 4, 27.

Courtin F., Jamonneau V., Duvallet G., Garcia A., Coulibaly B., Doumenge J.P., Cuny G. \& Solano P. Sleeping sickness in West Africa (1906-2006): changes in spatial repartition and lessons from the past. Tropical Medicine and International Health, 2008, 13, 334-344.

Courtin F., Sidibe I., Rouamba J., Jamonneau V., Gouro A. \& Solano P. Impacts des évolutions démographiques et climatiques sur la répartition spatiale des hommes, des tsé-tsé et des trypanosomoses en Afrique de l'Ouest. Parasite, 2009, 1, 3-10.

De la Rocque S., Michel J.F., Cuisance D., De Wispeleare G., Augusseau X., Guillobez S. \& Arnaud M. Le risque trypanosomien, une approche globale pour une décision locale. Édition du CIRAD, Montpellier, 2001.

Demenocal P.B. African climate change and faunal evolution during the Pliocene-Pleistocene. Earth and Planetary Science Letters, 2004, 220, 3-24.

DugGan A.J. The occurrence of human trypanosomiasis among the Rukuba tribe of Northern Nigeria. The Journal of Tropical Medicine and Hygiene, 1962, 65, 15-63.

DutTon J.E. Note on a Trypanosoma occurring in the blood of man. British Medical Journal, 1902, ii, 881-884.

Food and Agriculture Organization of the United Nations. State of the World's forests 2007. FAO, Rome, 2007.

FORD J. The role of the trypanosomiases in African ecology: a study of the tsetse-fly problem. Clarendon Press, Oxford, 1971.

Fournet F., Koné A., Traoré S. \& Hervouet J.P. Heterogeneity in the risk of sleeping sickness in coffee and cocoa commercial plantations in Ivory Coast. Medical and Veterinary Entomology, 1999, 13, 333-335. 
Simarro P.P., JANNin J. \& CATTAND P. Eliminating human african trypanosomiasis: where do we stand and what comes next. PLoS Medicine, 2008, 5, 174-180.

Stephens J.W.W. \& FAnTHAM H.B. On the peculiar morphology of a trypanosome from a case of sleeping sickness and the possibility of its being a new species (T. rhodesiense). Annals of Tropical Medicine and Parasitology, 1910, 4, 343-350.

United Nations. World population prospects: The 2006 revision. UN, New York, 2007.

United Nations. World urbanization prospects: The 2007 revision. UN, New York, 2008.

VANDERPLANCK F.L. The classification of Glossina palpalis, including the description of new subspecies and hybrids. Proceedings of the Royal Entomological Society London, 1949 18, 69-77.

Welburn S.C., FÈvre E.M., Coleman P.G., OditT M. \& Mauduin I. Sleeping sickness: a tale of two diseases. Trends in Parasitology, 2001, 17, 19-24.

World Health Organization. Control and surveillance of african trypanosomiasis. Report of a WHO Expert Committee. WHO, Geneva, 1998.

Reçu le 7 avril 2009

Accepté le 14 avril 2009 